\title{
Effective deployment of technology-supported management of chronic respiratory conditions: a call for stakeholder engagement
}

This article was published in the following Dove Press journal:

Pragmatic and Observational Research

5 July 2017

Number of times this article has been viewed

\author{
Richard W Costello \\ Alexandra L Dima ${ }^{2}$ \\ Dermot Ryan ${ }^{3}$ \\ R Andrew Mclvor ${ }^{4}$ \\ Kay Boycott ${ }^{5}$ \\ Alison Chisholm 6 \\ David Price ${ }^{7,8}$ \\ John D Blakey 9,10
}

'Department of Medicine, Royal College of Surgeons in Ireland, Dublin, Ireland; ${ }^{2}$ Amsterdam School of Communication Research ASCoR, University of Amsterdam, Amsterdam, the Netherlands; ${ }^{3}$ Allergy and Respiratory Research Group, Centre for Population Health Sciences, University of Edinburgh, Edinburgh, UK; ${ }^{4}$ Firestone Institute for Respiratory Health, McMaster University, Hamilton, ON, Canada; ${ }^{5}$ Asthma UK, London, ${ }^{6}$ Respiratory Effectiveness Group, Cambridge, ${ }^{7}$ Observational and Pragmatic Research Institute, Singapore; ${ }^{8}$ Academic Centre of Primary Care, University of Aberdeen, Aberdeen, ${ }^{9}$ Health Services Research, University of Liverpool, ${ }^{10}$ Respiratory Medicine, Royal Liverpool Hospital, Liverpool, UK
Correspondence: John D Blakey Royal Liverpool and Broadgreen University Hospitals NHS Trust, Prescot Street, Liverpool, Merseyside, L7 8XP, UK

Email jblakey@liverpool.ac.uk
Background: Healthcare systems are under increasing strain, predominantly due to chronic non-communicable diseases. Connected healthcare technologies are becoming ever more capable and their components cheaper. These innovations could facilitate both self-management and more efficient use of healthcare resources for common respiratory diseases such as asthma and chronic obstructive pulmonary disease. However, newer technologies can only facilitate major changes in practice, and cannot accomplish them in isolation.

Focus of review: There are now large numbers of devices and software offerings available. However, the potential of such technologies is not being realised due to limited engagement with the public, clinicians and providers, and a relative paucity of evidence describing elements of best practice in this complex and evolving environment. Indeed, there are clear examples of wasted resources and potential harm. We therefore call on interested parties to work collaboratively to begin to realize the potential benefits and reduce the risks of connected technologies through change in practice. We highlight key areas where such partnership can facilitate the effective and safe use of technology in chronic respiratory care: developing data standards and fostering inter-operability, making collaborative testing facilities available at scale for small to medium enterprises, developing and promoting new adaptive trial designs, developing robust health economic models, agreeing expedited approval pathways, and detailed planning of dissemination to use.

Conclusion: The increasing capability and availability of connected technologies in respiratory care offers great opportunities and significant risks. A co-ordinated collaborative approach is needed to realize these benefits at scale. Using newer technologies to revolutionize practice relies on widespread engagement and cannot be delivered by a minority of interested specialists. Failure to engage risks a costly and inefficient chapter in respiratory care.

Keywords: apps, smart inhaler, connected devices, remote monitoring, co-creation, standards, guidelines, health economics

\section{Introduction}

The traditional model of face-to-face healthcare delivery is becoming increasingly unsustainable as demand continues to increase. ${ }^{1}$ The introduction of new technologies has addressed demand and efficiency issues in other industries, and may permit costeffective solutions to healthcare needs. Chronic respiratory disease is a prototypical example of chronic care in which technology-mediated care might improve outcomes within a manageable cost framework. The potential of novel connected technologies must be considered in the context of the challenges associated with implementation at a large enough scale to provide sustainable solutions. In this article, we briefly review 
the types and promise of available solutions and then focus on solutions to overcome barriers and facilitate implementation.

\section{Healthcare systems under strain The need for new models of working}

Healthcare systems are under growing pressure from an aging and increasingly multimorbid population. ${ }^{2}$ Not only is the number of patients rising but so too is the complexity of presentations and the array of specialist tests and interventions tailored available to address individual patient needs. The combination of these factors has led to a growing resource crisis over the past decade. The Royal College of Physicians' Future Hospital Commission Report ${ }^{3}$ observes that had the change in health system demands taken place over the period of a year, it would have been deemed a "national disaster" prompting a suitable response. Yet the fact it has "crept up" has resulted in a distinct lack of direct action.

Different healthcare systems face different pressures. In lower income countries, there are growing populations and a scarcity of resources and trained healthcare staff. ${ }^{4}$ In higher income countries, there is a growing awareness that overuse of tests and investigations is wasteful and potentially harmful, ${ }^{5}$ leading to initiatives such as the Choose Wisely Campaign. ${ }^{6}$ It is evident that usual models of face-to-face patient-physician consultation in out-patient or community settings will become increasingly stretched and unable to provide safe and timely care. New ways of working are required to allow clinicians to support effective self-management at scale. This will require remote data capture in a way that enables their subsequent incorporation into existing clinical records, controls for the limitations of self-report, and captures the influence of external environmental and seasonal influences on disease state. This would allow reliable benchmarking against care patterns and thus integration of patient stratification algorithms into intelligent Clinical Decision Support Systems (CDSS).

\section{Chronic respiratory disease as a prototype for technology-supported management}

Over 500 million people worldwide have chronic airways disease, with many millions more experiencing common conditions such as sleep disordered breathing and pulmonary fibrosis. ${ }^{7}$ Individuals with chronic lung diseases also have a higher prevalence of chronic comorbidities related to their conditions and related treatments such as cardiovascular disease, diabetes, obesity, osteoporosis and depression. ${ }^{8}$ Engaging with people who have a respiratory diagnosis can, therefore, also present an opportunity for positive interventions in these areas. Thus, respiratory medicine is well positioned as a conduit for new ways of working that focus on supporting shared care and self-management through improvements in remote assessment and monitoring.

\section{The concept: what can new technologies offer? Monitoring diseases, behavior and their context}

The past decade has seen a steep change in areas of technology relevant to healthcare. Sensors related to physiological measurement have become smaller, cheaper, more capable and more accurate. ${ }^{9,10}$ This provides the possibility of remote assessment and monitoring of health and disease. ${ }^{11}$ Tools such as electronic peak flow meters can provide standardized time-stamped information that can inform clinical decisionmaking. ${ }^{12}$ Devices are not only becoming evermore capable and flexible, but also increasingly affordable, ubiquitous and interconnected. There are exciting possibilities to gather data from a user's daily activities to contextualize and enrich monitoring data. This may be through existing devices such as activity monitors, or by adding sensors to items the individual uses daily such as an inhaler. Moving toward the "Internet of Things" has the potential to reduce issues with stand-alone telehealth systems that require dedicated time for interactions using operating systems unfamiliar to the user. ${ }^{13,14}$ The large volume of data recorded by sensors in mobile devices can be stored and analyzed close to the point of capture, and can be combined with other information in the cloud such as atmospheric, pollen count or pollution data (Figure 1).

\section{Intervention based on novel data}

Remote monitoring connected to the patient's own phone or computer offers more opportunities to promote behavioral change. Repeated, in-context feedback prompted by modest amounts of specific information may support more sustained improvements than an annual review based on a large volume of (often historic) information. For example, results of a measure of interest (e.g., taking inhalers regularly) can be fed back to the user and compared against a personal history and target standards, and linked to specific adherence interventions, such as daily reminders for missed doses, visual feedback of monthly performance, or advice by a healthcare professional. This simple feedback of current behavior is only one aspect of an ideal, carefully-designed, integrated system of assessment and intervention. Such a system could address a range of specific patient behaviors: 


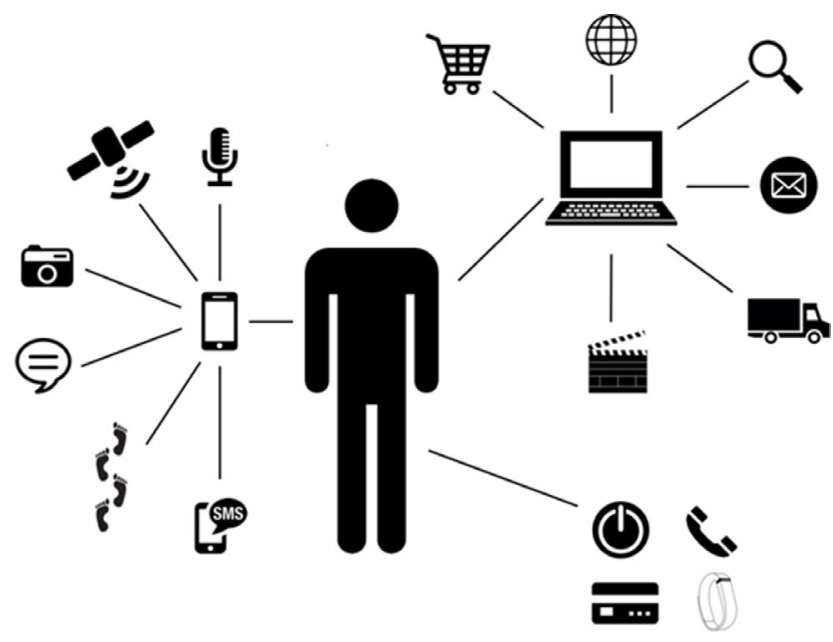

Figure I Sources of health and contextualising data other than disease-specific apps or devices.

supporting self-regulatory capacity and skills, encouraging adjuvant activities, and providing information that emphasises opportunities and choice. ${ }^{15}$

Yet it is not only patient behavior that may be altered in this way; new monitoring technologies offer a major opportunity to shape and guide clinicians and their practice behaviors. Moreover, the availability of multimodal remote assessment could increase the confidence of clinicians in undertaking "n of 1 " trials of treatment, a valuable asset in heterogeneous conditions such as asthma. ${ }^{16}$ As newer technologies become widely adopted, data from remote sensors will be incorporated into decision support tools, including risk prediction models. This could permit faster and more consistent clinical review, particularly if care is fragmented across several providers.

\section{Current state of remote monitoring and assessment}

There is evidently great potential in the use of remote monitoring and connected technologies for chronic respiratory conditions. At the time of writing, two main types of technology are being offered to attempt to realize some of this potential: mobile phone application and connected devices.

\section{Mobile phone applications}

Recent reports estimate there are over 150,000 apps, developed by thousands of companies and individuals. ${ }^{17}$ The majority of these are in English, but the Chinese and other global markets are rapidly expanding. ${ }^{18}$ The number of apps available suggests individuals are willing to engage with this platform for education or support (Figure 2). A recent American study found that more than half of smartphone

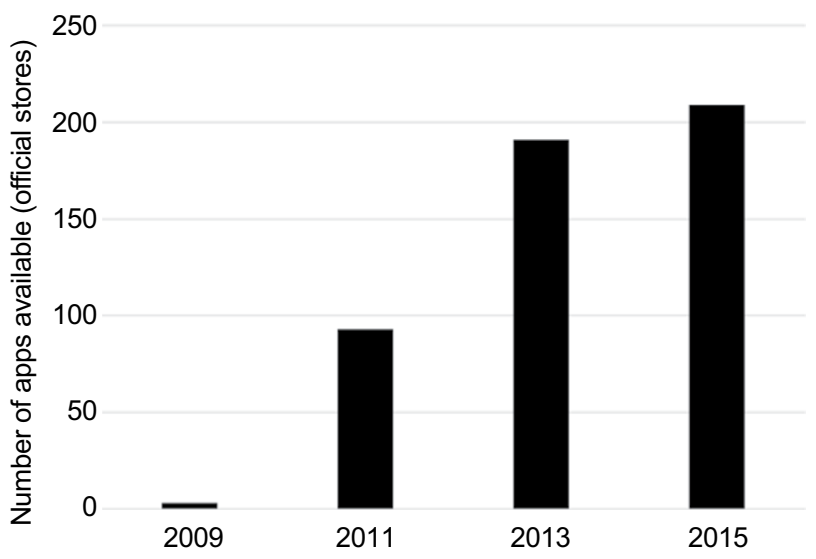

Figure 2 Number of available mobile phone applications for asthma. Note: Data from Burbank et al and Wu et al. ${ }^{21,57}$

users had downloaded a health-related app and placed high levels of trust in their accuracy. ${ }^{19}$ This enthusiasm appears to extend to respiratory disease as over $90 \%$ of adolescents using personal asthma action plans based on a mobile device reported they felt better able to manage their asthma. ${ }^{20}$

However, the large and increasing number of apps available also suggests that, despite consumer and developer enthusiasm, there are few offerings that fulfill their remit and are widely and persistently used..$^{21}$ This may reflect the lack of clinical benefit from stand-alone software: a large UK-based randomized controlled trial of a mobile phone app for asthma monitoring demonstrated no clinical benefit, but added expense. ${ }^{22}$

From the clinical perspective, mobile applications herald the potential to support clinicians' decision-making by (for example) facilitating multifactorial risk assessment calculations ${ }^{23}$ or assisting in attitudinal profiling. ${ }^{24}$ It remains uncertain how much value is added by the delivery through a mobile device beyond other interfaces that may be less costly.

\section{Connected devices}

Low-cost electronics integrated with standard equipment now permit the collection and combination of routine data such as weight and peak expiratory flow. Similar technology allows the monitoring of medication administration such as that used in so-called smart inhalers, now a well-established research too $^{25-27}$ beginning to see targeted use in clinical settings. ${ }^{28}$

Ingestible technologies also show promise for oral medication. ${ }^{29}$ Tools such as pulse oximeters and activity monitors that were confined to in-patient or specialist use are now routine consumer products ${ }^{30}$ and could be incorporated into smartphones. ${ }^{31}$ As the data from these monitors can now be collected into existing platforms, such as Apple Health, the 
development burden on small to medium enterprises (SMEs) is potentially reduced and the market is likely to become increasingly congested. ${ }^{32}$

As with mobile apps, connected devices often secure initial engagement but their long-term clinical benefit is less clear. Although devices such as smart inhalers provide accurate data, ${ }^{33}$ they have not yet been studied as part of a holistic behavioral change system. Small studies of the isolated introduction of smart inhalers have not shown an increase in medication adherence or symptom improvement. ${ }^{34}$

\section{Technologies as a potential hazard Primum non nocere}

New ways of working are always accompanied by new challenges and risks. Historically, most medical innovations and technologies have been developed to rigorously-defined safety standards. Emerging technologies such as apps and smart devices, however, are made available directly to consumers, seldom with peer-reviewed publications describing their scientific rationale or reported effectiveness. The absence of the usual levels of protection afforded to patients' risks lower quality standards, such as software that contain errors in advice or miscalculated peak flow measurements, reaching the patient unimpeded..$^{21}$ The combination of potentially inaccurate measurement and algorithmic misinterpretation is a concern in this large and growing market. The QRISK $^{\circledR}$ cardiovascular risk assessment tool, for example, is integral to many thousands of healthcare interactions in UK primary care practice. Yet it was found to contain a calculation error that could erroneously recommend the commencement of statin therapy, resulting in a suspension of its use in $2015 .^{35}$

The rapid evolution of information technologies requires intelligent synthesis of vast amounts of data and expert opinion and presentation in a readily accessible format if it is to be meaningfully used. The generation and curation of mass amounts of data often outpaces data visualization capabilities and infrastructure and can raise challenging ethical dilemmas. Devices such as continuous positive airway pressure (CPAP) machines are now able to transfer data directly to providers, ${ }^{36}$ and mechanisms are being rolled out to permit patients to upload information directly into their primary care records. ${ }^{37}$ It is unclear if patients believe the data stream from their device is being continuously monitored, and (if so) what the implications of this understanding might be on the personal level of responsibility patients assume for their wellbeing.

\section{Data security}

The practice of medicine is predicated on confidentiality between clinician and patient. In recent years, however, connected technologies to manage chronic conditions or promote healthy living have raised new issues in patient confidentiality. Recognition of the potential use of video communication platforms such as Skype, ${ }^{38-40}$ for example, has led to the suggestion that it may sometimes be in a patient's best interest to trade off absolute data security against the value of receiving a remote specialist opinion: "better cured than secured." In the context of smart phones and connected devices as self-management supports, connectivity results in a convergence of commercial, clinical and research perspectives on data management and confidentiality.

In addition to breaches of confidentiality at the individual patient level, cyber-attacks against healthcare providers are increasingly becoming common and the industry is lagging behind others in its capability to secure vital data. ${ }^{41}$ It seems unlikely that app and device providers will be able to ensure data security in the face of evermore sophisticated cyber-attacks. Such data breaches may have serious consequences for individuals, particularly if sensitive incidental data is captured or individual devices can be remotely manipulated. ${ }^{42}$ Also of concern, at a population level, is the increasing commercialization of healthcare data by providers. Healthcare records are sold en masse to industry and users of health-related apps and websites and used to inform targeted advertising. Data on visits to UK National Health Service webpages, for example, is now being shared with Amazon. ${ }^{43}$

In the preceding sections, we have described the potential and increasing availability of connected technologies and targeted software. We have also highlighted the relative lack of study data supporting their routine clinical use, and the potential risks of uncontrolled implementation. The respiratory community therefore faces a major challenge and intervention is required to understand why technology-based solutions are not fulfilling their potential so that the relevant issues can be appropriately addressed.

\section{Why might technology based solutions not fulfil their potential?} Economics

Medical apps are usually created by small enterprises and offered free or at minimal cost (on average $<£ 1$ ). ${ }^{44} \mathrm{At}$ such low levels of return, there is little capacity or incentive for investment in research and development to deliver high-quality medical products, certainly in comparison to the activity of pharmaceutical companies. This issue is compounded by the 
rate of change in operating systems and hardware platforms: there is a race to deliver apps to market before they are no longer technically functional. In contrast, the approvals process for medical interventions is lengthy and technical. Developers receive relatively little return on investment and, as they are not usually healthcare providers, do not stand to gain from the health benefits their app may afford. An important step toward future technologies potentially having greater clinical value and longevity would therefore appear to be co-production with providers. This concept might focus efforts on interventions where there is a clinical and financial step-change, such as reducing hospital admissions or the use of high-cost drugs. Co-production would also ensure both parties have a clear understanding of the financial implications of deploying a new technology beyond the unit cost (personnel training, infrastructure, etc.). Involving payers in co-production may also reduce the drive for desire- rather than need-led content development (Figure 3).

\section{Utility}

A notable aspect of many apps and connected devices is the lack of clarity in their specific purpose. As with any medical intervention, the likelihood of efficacy is dependent on defining a target population, a specific intervention, and a primary outcome. The all-encompassing approach of most apps may be influenced by a relative lack of understanding of respiratory diseases, or market forces pushing developers to seek the largest potential market. Most apps are not developed in consultation with experts or patients. ${ }^{45,46}$ It is apparent that co-production with end users could help focus development on relevant and tractable clinical and behavioral or activation problems. This may begin to address the current "solution first" issue of new technologies being brought to market without first establishing they are appropriately addressing a meaningful issue. ${ }^{47}$ Co-production between clinicians and

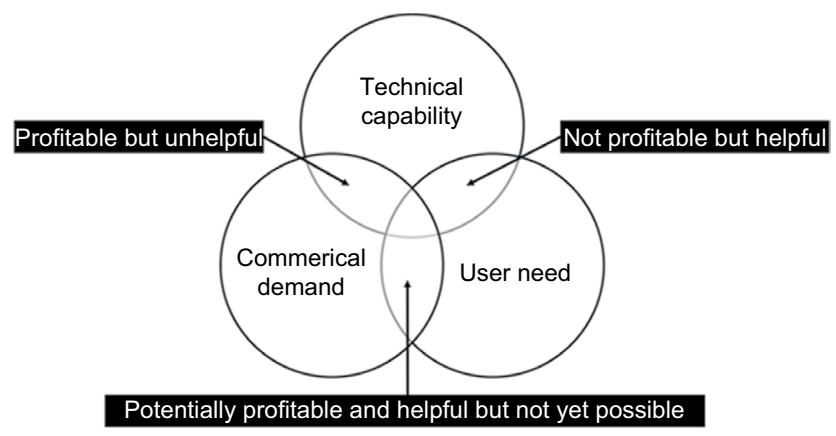

Figure 3 Technology-based solutions can be considered in terms of current technical capability, clinical requirement, and commercial demand. patients (as previously discussed) could reduce the focus on technical capability and focus instead on utility and data that can be successfully and meaningfully curated.

Demonstrating effectiveness, even of well-designed technologies, may also be a challenge, especially if it is aimed at hard-to-reach individuals who do not usually engage with health services. A randomized controlled trial of mobile phone-based self-monitoring for adolescents with asthma recruited only $2.4 \%$ of those invited. ${ }^{22}$ This lack of engagement may also reflect a gap in perceived quality between the health-related technology on offer and other consumer technologies.

The rush to market to capitalize on evolving functionality and avoid obsolescence inevitably limits the time spent incorporating ergonomic principles ${ }^{48}$ into the design of technologies or consulting with potential end-users before being launched. This is particularly true for SMEs that lack institutional memory. Resultant offerings may have shortcomings in their high demand for data entry, suboptimal interface, limited functionality, and information provision ${ }^{49}$ that limit user engagement. In the longer term, these issues may be partially overcome through applying new software behind common social media platforms such as Facebook or intelligent assistants such as Siri. However, co-production with patients will remain an essential component of successful software or device design. Engagement with patient organizations and charities will facilitate the design and testing process, ${ }^{50}$ as will developers leveraging learning from other projects such as the large European Union-funded collaborative study MyAirCoach (http://www.myaircoach.eu/myaircoach/). A further challenge in achieving true functional effectiveness will be the routine integration and interoperability of the device and/ or the data collected within the patient electronic healthcare record $^{51}$ and within integrated healthcare pathways. ${ }^{52}$

\section{Creating an environment conducive to development and deployment Current standards}

Although regulators classify apps or devices that record data on health or disease, those that stop short of suggesting an alteration or that essentially digitize previously paper-based data forms are largely classified as "non-medical". As a result, there is widespread use of unregulated connected devices and apps with the potential to influence health behaviors and limited high-quality independent information available to guide users in navigating the options available to them. Furthermore, as noted, the great majority of these offerings have not been robustly developed or tested. Not only does 
this mean individual apps or devices are often flawed in terms of their basic functionality, but it is also unclear if their use is associated with any benefit. ${ }^{53}$ The lack of generalizable knowledge from robust research studies is further hampering the iterative improvement of technology-supported management. Developers and clinicians must attempt to keep abreast of scanty information scattered across journal articles, webpages, white papers, and reports.

In response to this broad issue, many standards, checklists, and guidelines have been produced on the implementation of e-health, and there is now an e-health aspect to most recommendations for complex interventions. The World Health Organization mHealth Technical Evidence Review Group has also developed a checklist for mHealth Evidence Reporting and Assessment (mERA) ${ }^{54}$ (Table 1). The mERA document is welcome, but does highlight two key limitations common to such recommendations. Although it provides a solid basis for assessing reports of studies of technology supported care, it gives little attention to the specifics of intervention development: there is a mention of "user feedback" but no

Table I World Health Organization mERA reporting checklist for respiratory studies

\begin{tabular}{|c|c|c|}
\hline Criteria & $\begin{array}{l}\text { Item } \\
\text { no }\end{array}$ & Notes \\
\hline Infrastructure (population level) & I & $\begin{array}{l}\text { Clearly presents the availability of infrastructure to support technology operations in the study location. } \\
\text { This refers to physical infrastructure such as electricity, access to power, connectivity etc. in the local } \\
\text { context. Reporting X\% network coverage rate in the country is insufficient if the study is not being } \\
\text { conducted at the country level }\end{array}$ \\
\hline Technology platform & 2 & $\begin{array}{l}\text { Describes and provides justification for the technology architecture. This includes a description of } \\
\text { software and hardware and details of any modifications made to publicly available software }\end{array}$ \\
\hline Interoperability/ HIS context & 3 & $\begin{array}{l}\text { Describes how mHealth intervention can integrate into existing health information systems. Refers to } \\
\text { whether the potential of technical and structural integration into existing HIS or program has been } \\
\text { described, irrespective of whether such integration has been achieved by the existing system }\end{array}$ \\
\hline Intervention delivery & 4 & $\begin{array}{l}\text { The delivery of the mHealth intervention is clearly described. This should include frequency of mobile } \\
\text { communication, mode of delivery of intervention (that is, SMS, face-to-face, interactive voice response), } \\
\text { timing and duration over which delivery occurred }\end{array}$ \\
\hline Intervention content & 5 & $\begin{array}{l}\text { Details of the content of the intervention are described. Source and any modifications of the } \\
\text { intervention content is described }\end{array}$ \\
\hline Usability/content testing & 6 & $\begin{array}{l}\text { Describe formative research and/or content and/or usability testing with target group(s) clearly } \\
\text { identified, as appropriate }\end{array}$ \\
\hline User feedback & 7 & $\begin{array}{l}\text { Describes user feedback about the intervention or user satisfaction with the intervention. User feedback } \\
\text { could include user opinions about content or user interface, their perceptions about usability, access, } \\
\text { connectivity, etc }\end{array}$ \\
\hline Access of individual participants & 8 & $\begin{array}{l}\text { Mentions barriers or facilitators to the adoption of the intervention among study participants. Relates to } \\
\text { individual-level structural, economic and social barriers or facilitators to access such as affordability, and } \\
\text { other factors that may limit a user's ability to adopt the intervention }\end{array}$ \\
\hline Cost assessment & 9 & $\begin{array}{l}\text { Presents basic costs assessment of the mHealth intervention from varying perspectives. This criteria } \\
\text { broadly refers to the reporting of some cost considerations for the mHealth intervention in lieu of a full } \\
\text { economic analysis. If a formal economic evaluation has been undertaken, it should be mentioned with } \\
\text { appropriate references. Separate reporting criteria are available to guide economic reporting }\end{array}$ \\
\hline Adoption inputs/program entry & 10 & $\begin{array}{l}\text { Describes how people are informed about the program, including training, if relevant. Includes } \\
\text { description of promotional activities and/or training required to implement the mHealth solution among } \\
\text { the user population of interest }\end{array}$ \\
\hline Limitations for delivery at scale & II & Clearly presents mHealth solution limitations for delivery at scale \\
\hline Contextual adaptability & 12 & $\begin{array}{l}\text { Describes the adaptation, or not, of the solution to a different language, different population or context. } \\
\text { Any tailoring or modification of the intervention that resulted from pilot testing/usability assessment is } \\
\text { described }\end{array}$ \\
\hline Replicability & 13 & $\begin{array}{l}\text { Detailed intervention to support replicability. Clearly presents the source code/screenshots/flowcharts } \\
\text { of the algorithms or examples of messages to support replicability of the mHealth solution in another } \\
\text { setting }\end{array}$ \\
\hline Data security & 14 & Describes the data security procedures/confidentiality protocols \\
\hline $\begin{array}{l}\text { Compliance with national } \\
\text { guidelines or regulatory statutes }\end{array}$ & 15 & $\begin{array}{l}\text { Mechanism used to assure that content or other guidance/information provided by the intervention is in } \\
\text { alignment with existing national/regulatory guidelines and is described }\end{array}$ \\
\hline Fidelity of the intervention & 16 & $\begin{array}{l}\text { Was the intervention delivered as planned? Describe the strategies employed to assess the fidelity of } \\
\text { the intervention. This may include assessment of participant engagement, use of backend data to track } \\
\text { message delivery and other technological challenges in the delivery of the intervention }\end{array}$ \\
\hline
\end{tabular}

Abbreviations: HIS, health information systems; mERA, mHealth Evidence Reporting and Assessment. 
Box I Facilitatory conditions for the widespread deployment of technology supported respiratory management

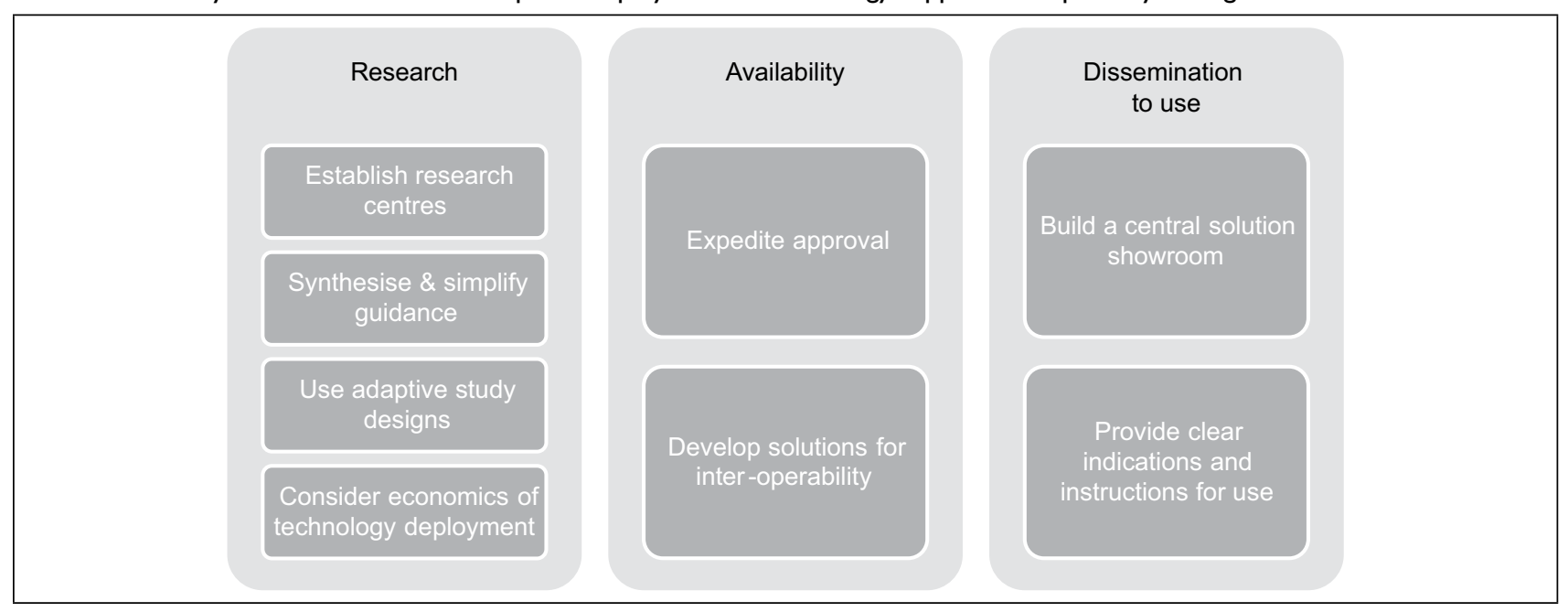

details of co-development with clinicians, payers or patients. There is also little practical guidance for innovators on how the evidence requested might be generated.

\section{Practical steps to widespread deployment}

Respiratory clinicians and healthcare providers should be wary of deploying any technology-based solution that is not supported by a peer-reviewed publication that complies with the mERA reporting guidance or any subsequently developed respiratory-specific iteration of this. However, as a community, it is essential that careful thought is given to the pragmatic question of how robust evidence for a device or software can be delivered and disseminated before the technology becomes outdated and/or loses its commercial advantage.

We propose that eight core areas of activity would help facilitate the development of needed solutions, assess their effectiveness and support their implementation in an engaged community of people with respiratory disease and the clinicians with whom they interact (summarized in Box 1).

\section{Research}

\section{Establish research centers}

SMEs do not have the budget to undertake clinical studies in the same manner as major pharmaceutical companies. Establishing innovative testing facilities for connected technologies could enable innovators to access relevant protocols, experts and patient groups in a timely and cost-effective manner. This will require initial investment from healthcare providers or research funders but will improve co-production, research volume and quality. Asthma UK's AsthmaLab is an example of a charitable organization piloting a co-creation approach to digital health solutions focused on asthma. This type of approach explores how to harness the willingness of both people with asthma and asthma-interested clinicians to volunteer to develop robust, agile, cost effective testing. Centers with a focus on research in this area can also act as hubs from which to disseminate results, highlighting how newer technologies can provide opportunities to improve respiratory care.

\section{Synthesize and simplify guidance}

The amount of information on common respiratory conditions, behavior change, intervention development, implementation science, and medical research methods is overwhelming to non-specialists. Parsimonious diseasespecific guidelines for developing technology-mediated management solutions for common conditions, disseminated in a user-friendly format to current and potential developers would be of significant benefit. These guidelines, developed in collaboration with all stakeholders, could also provide background financial information to support the movement toward mature health economic models for new technologies. When choosing an app or device, end-users could simply check the relevant guidelines had been adhered to in order to facilitate and improve their decision-making.

\section{Use adaptive study designs}

There is a growing recognition of the need to adopt newer, more flexible and responsive trial designs to address clinical management questions in current practice. ${ }^{55}$ The use of adaptive designs and umbrella trials will better facilitate the 
evaluation of multiple solutions with fewer restrictions on other aspects of care. New trial designs can also be used to understand highly contextualized behavior in subgroups. Methodologists and researchers could promote the use of such methods by developing practical guides and highlighting best practice examples. The increased efficiency of newer study designs may also reassure participants that they are far less likely to face relatively long-term allocation to a study arm that uses an unhelpful or outmoded technology.

\section{Consider the economics of technology deployment}

Our understanding of how best to deploy new technologies lags behind the technical development. Research is required to investigate the optimal method of incorporating new data streams into CDSS and, crucially, into the health economics around deployment. It is unclear which technologies represent good value when costs of training staff, educating patients, improving technical infrastructure and managing plentiful data are taken into consideration: only when more mature health economic models are available will there be a clear picture of the role of connected devices going forward. This would require close collaboration between health providers and health economists to develop and promote the use of such models. The potential cost and time efficiencies of using newer technologies should motivate clinicians to seek out such collaborations.

\section{Availability}

\section{Expedite approval}

Regulators such as the US Food and Drug Administration and the UK's Medicines Healthcare Products Regulatory Authority have developed clear guidance explaining which innovations should be subject to their approval system. However, developers are still reluctant to pursue approval as they perceive the process to be time-consuming and complex. We urge regulators to continue to engage with healthcare providers and developers to ensure approvals can be made in a timely fashion, potentially with the introduction of new, proportionate pathways.

\section{Develop solutions for inter-operability}

To leverage the potential of newer technologies fully, it will be essential to share data between sensors, mobile devices, and patient records. A good deal of work is still to be done to agree standards for routinely collected data, with the concern that we may end up with multiple unconnected devices and pieces of software. These would then rely on manual review and repetitive information transfer (with the risk that historic data could be lost) and the additional cost of users repeatedly needing to learn new interfaces. Solutions for inter-operability need urgent consideration by technology specialists. These specialists should find other stakeholders such as health providers and motivate end-users (clinicians, patients) to contribute to these discussions as they seek to avoid time-consuming and frustrating incompatibility issues.

\section{Dissemination to use}

\section{Build a central solution showroom}

It is insufficient to develop and approve innovative solutions without a clear framework for their dissemination to intended end-users in an accessible and engaging manner. There have been some initiatives to create such an offering (e.g., the Health Tools Library ${ }^{56}$ ), but we currently lack a system whereby a person with a chronic respiratory condition or a nurse in primary care could easily identify and access a high-quality product suitable for them. Such an initiative would have a short-term benefit for health providers, professionals and people with respiratory disease, so should attract their engagement in development, alongside patient organizations. Using a showroom to highlight potential benefits and to make it easier to access technology based solutions improves the likelihood of timepressured or more sceptical end-users trying new approaches.

\section{Provide clear indications and instructions for use}

Medical interventions proven effective in research studies should be used in a manner that is consistent with those studies. In usual practice, decisions are informed by guidelines and appropriate prescribing is safeguarded by pharmacists. In contrast, new technologies are less likely to feature by name in guidelines given their relative rate of revision, and there will be less oversight of delivery to patients. Learned institutions and healthcare providers will therefore need to produce clear general guidance on the practicalities of implementation, and invest in training staff on applying this guidance in routine care. Individual products require a standardized summary of characteristics provided by developers in line with this guidance to facilitate their rapid integration in routine care. Clinicians delivering respiratory care will have more confidence in recommending new technologies to patients with this familiar style of infrastructure, increasing their experience and engagement in this developing area.

\section{Conclusion}

The increasing demand on healthcare services consequent to increasing prevalence of chronic diseases cannot be addressed 
using traditional working practices. The large-scale deployment of newer connected technologies has the potential to empower self-management in respiratory diseases and facilitate expert review. However, this would require major changes in the way respiratory diseases are currently managed. These changes can only be realised through diverse collaborative efforts in research and clinical care, not left to the technology-interested minority. To achieve the required goals, innovative products must be developed in partnership with patients, clinicians, and providers. These products must be robustly tested and approved using newer approaches, but they must also be readily accessed and used.

We believe that we are at a tipping point in the management of chronic respiratory disease. Unless all parties work collaboratively to realize the potential benefits, the thousands of flowers of innovation that are beginning to bloom will die in the absence of facilitatory conditions, accepted development quality standards, robust verification of utility, and ready access for end-users. If this does not occur, technologies will remain a confusing and expensive distraction at a time when resources are increasingly stretched.

\section{Acknowledgments}

We are grateful to Joseph Clift, Daisy Ellis, and Dan Poscover for constructive discussions in this area.

This manuscript is based on discussions that took place around meetings of the Respiratory Effectiveness Group.

\section{Author contributions}

JDB, AC and ALD had the initial idea for the manuscript. RWC, JDB and DR drafted initial sections. The concept and content were revised at meetings with RAM, KB, and DP. The manuscript was finalized by ALD, AC and JDB and all authors approved this. All authors contributed toward data analysis or literature search, drafting and revising the paper and agree to be accountable for all aspects of the work.

\section{Disclosure}

RWC has a patent on the use of acoustic analysis to assess inhaler use. DP has previously had research funding to develop software to assess inhaler technique. The other authors report no conflicts of interest in this work.

\section{References}

1. Bousquet J, Jorgensen C, Dauzat M, et al. Systems medicine approaches for the definition of complex phenotypes in chronic diseases and ageing. From concept to implementation and policies. Curr Pharm Des. 2014;20(38):5928-5944.

2. Barnett K, Mercer SW, Norbury M, Watt G, Wyke S, Guthrie B. Epidemiology of multimorbidity and implications for health care, research, and medical education: a cross-sectional study. Lancet. 2012;380(9836):37-43.
3. Future hospital: caring for medical patients. A report from the Future Hospital Commission to the Royal College of Physicians. London: Future Hospital Commission; 2013. Available from: https://www. rcplondon.ac.uk/projects/outputs/future-hospital-commission. Accessed May 3, 2017.

4. World Health Organisation. Global Strategy on Human Resources for Health: Workforve 2030. Geneva: World Health Organisation; 2016.

5. Prasad V, Vandross A, Toomey C, et al. A decade of reversal: an analysis of 146 contradicted medical practices. Mayo Clin Proc. 2013;88(8):790-798.

6. Cassel CK, Guest JA. Choosing wisely: helping physicians and patients make smart decisions about their care. JAMA. 2012;307(17):1801-1802.

7. Marciniuk D, Ferkol T, Nana A, et al. Respiratory Diseases in the World: Realities of today, Opportunities for Tomorrow. Forum of International Respiratory Societies; 2013. Availabe from: https://www.ersnet.org/pdf/ publications/firs-world-report.pdf. Accessed March 29, 2017.

8. Gershon AS, Wang C, Guan J, To T. Burden of comorbidity in individuals with asthma. Thorax. 2010;65(7):612-618.

9. Ciuti G, Ricotti L, Menciassi A, Dario P. MEMS sensor technologies for human centred applications in healthcare, physical activities, safety and environmental sensing: a review on research activities in Italy. Sensors (Basel). 2015;15(17):6441-6468.

10. Wang C, Lu W, Narayanan MR, Redmond SJ, Lovel NH. Low-power technologies for wearable telecare and telehealth systems: a review. Biomed Eng Lett. 2015;5(1):1-9.

11. Piwek L, Ellis DA, Andrews S, Joinson A. The rise of consumer health wearables: promises and barriers. PLoS Med. 2016;13(2):e1001953.

12. Meuric S, Leroy M, Raffestin B, Bidat E. Compliance with and acceptability of a new electronic peak flow meter, the PiKo-1. Rev Des Mal Respir. 2005;22(6 Pt 1):935-941.

13. Greenhalgh T, Procter R, Wherton J, Sugarhood P, Hinder S, Rouncefield $\mathrm{M}$. What is quality in assisted living technology? The ARCHIE framework for effective telehealth and telecare services. BMC Med. 2015;13:91.

14. Lai AM, Kaufman DR, Starren J, Shea S. Evaluation of a remote training approach for teaching seniors to use a telehealth system. Int J Med Inform. 2009;78(11):732-744.

15. Michie S, Wood CE, Johnston M, Abraham C, Francis JJ, Hardeman W. Behaviour change techniques: the development and evaluation of a taxonomic method for reporting and describing behaviour change interventions (a suite of five studies involving consensus methods, randomised controlled trials and analysis of qualitative data). Health Technol Assess. 2015;19(99):1-188.

16. Schork NJ. Personalized medicine: time for one-person trials. Nature 2015;520(7549):609-611.

17. Costello S. How Many Apps are in the App Store?; 2016. Available from: https://www.lifewire.com/how-many-apps-in-app-store-2000252. Accessed March 29, 2017.

18. Perez S. China overtakes the U.S. in iOS App Store revenue; 2016. Available from: https://techcrunch.com/2016/10/20/china-overtakesthe-u-s-in-ios-app-store-revenue/. Accessed March 29, 2017.

19. Krebs P, Duncan DT. Health app use among us mobile phone owners: a national survey. JMIR Mhealth Uhealth. 2015;3(4):e101.

20. Burbank AJ, Lewis SD, Hewes M, et al. Mobile-based asthma action plans for adolescents. J Asthma. 2015;52(6):583-586.

21. Huckvale K, Morrison C, Ouyang J, Ghaghda A, Car J. The evolution of mobile apps for asthma: an updated systematic assessment of content and tools. BMC Med. 2015;13:58.

22. Ryan D, Price D, Musgrave SD, et al. Clinical and cost effectiveness of mobile phone supported self monitoring of asthma: multicentre randomised controlled trial. BMJ. 2012;344:e1756.

23. Blakey JD, Price DB, Pizzichini E, et al. Identifying risk of future asthma attacks using UK medical record data: a respiratory effectiveness group initiative. J Allergy Clin Immunol Pract. 2016.

24. David-Wang A, Price D, Cho SH, et al. Development and validation of an attitudinal-profiling tool for patients with asthma. Allergy Asthma Immunol Res. 2017;9(1):43-51.

25. Patel M, Pilcher J, Reddel HK, et al. Predictors of severe exacerbations, poor asthma control, and beta-agonist overuse for patients with asthma. J Allergy Clin Immunol Pract. 2014;2(6):751-758. 
26. Sulaiman I, Cushen B, Greene G, et al. Objective assessment of adherence to inhalers by COPD patients. Am J Respir Crit Care Med. 2017;195(10):1333-1343.

27. Merchant RK, Inamdar R, Quade RC. Effectiveness of population health management using the propeller health asthma platform: a randomized clinical trial. J Allergy Clin Immunol Pract. 2016;4(3):455-463.

28. Heaney LG, Djukanovic R, Woodcock A, et al. Research in progress: Medical Research Council United Kingdom Refractory Asthma Stratification Programme (RASP-UK). Thorax. 2016;71(2):187-189.

29. Belknap R, Weis S, Brookens A, et al. Feasibility of an ingestible sensorbased system for monitoring adherence to tuberculosis therapy. PLoS One. 2013;8(1):e53373.

30. Lipnick MS, Feiner JR, Au P, Bernstein M, Bickler PE. The accuracy of 6 inexpensive pulse oximeters not cleared by the food and drug administration: the possible global public health implications. Anesth Analg. 2016;123(2):338-345.

31. Freedman B. Screening for atrial fibrillation using a smartphone: is there an app for that? J Am Heart Assoc. 2016;5(7).

32. Patrick JR. How mHealth will spur consumer-led healthcare. mHealth. 2015;1:14.

33. Pilcher J, Holliday M, Ebmeier S, et al. Validation of a metered dose inhaler electronic monitoring device: implications for asthma clinical trial use. BMJ Open Respir Res. 2016;3(1):e00128.

34. Morton RW, Elphick HE, Rigby AS, et al. STAAR: a randomised controlled trial of electronic adherence monitoring with reminder alarms and feedback to improve clinical outcomes for children with asthma. Thorax. 2017;72(4):347-354.

35. Matthews-King, A. Pulse. London: Cogora Ltd; 2016.

36. Stepnowsky CJ, Palau JJ, Marler MR, Gifford AL. Pilot randomized trial of the effect of wireless telemonitoring on compliance and treatment efficacy in obstructive sleep apnea. J Med Internet Res. 2007; 9(2):e14.

37. Taylor J. Liverpool Echo. Liverpool: Trinity Mirror; 2015.

38. Mosier J, Joseph B, Sakles JC. Telebation: next-generation telemedicine in remote airway management using current wireless technologies. Telemed J E Health. 2013;19(2):95-98.

39. Glauser W. The skype solution. CMAJ. 2011;183(12):E798.

40. Rainey S. The Spectator. London: Spectator 1828 Ltd; 2014.

41. Luna R, Rhine E, Myhra M, Sullivan R, Kruse CS. Cyber threats to health information systems: a systematic review. Technol Health Care. 2016;24(1):1-9.
42. Clery D. The privacy arms race. Could your pacemaker be hackable? Science. 2015;347(6221):499.

43. Libert T, Grande D, Asch DA. What web browsing reveals about your health. BMJ. 2015;351:h5974.

44. Liu CZ, Au YA, Choi HS. Effects of freemium strategy in the mobile app market: an empirical study of google play. J Manage Inf Syst. 2014;31(3):326-354.

45. Hamilton AD, Brady RR. Medical professional involvement in smartphone 'apps' in dermatology. Br J Dermatol. 2012;167(1):220-221.

46. Rosser BA, Eccleston C. Smartphone applications for pain management. J Telemed Telecare. 2011;17(6):308-312.

47. McCartney M. How do we know whether medical apps work? BMJ. 2013;346:f1811.

48. Martin JL, Norris BJ, Murphy E, Crowe JA. Medical device development: the challenge for ergonomics. Appl Ergon. 2008;39(3):271-283.

49. Stoyanov SR, Hides L, Kavanagh DJ, Zelenko O, Tjondronegoro D, Mani M. Mobile app rating scale: a new tool for assessing the quality of health mobile apps. JMIR Mhealth Uhealth. 2015;3(1):e27.

50. Bartlett SJ, Barnes T, McIvor RA. Integrating patients into meaningful real-world research. Ann Am Thorac Soc. 2014;11(Suppl 2):S112-117.

51. Marceglia S, Fontelo P, Rossi E, Ackerman MJ. A standards-based architecture proposal for integrating patient mhealth apps to electronic health record systems. Appl Clin Inform. 2015;6(3):488-505.

52. European Innovation Partnership on Active and Healthy Ageing, Action Plan B3; Mechanisms of the Development of Allergy, WP 10; Global Alliance against Chronic Respiratory Diseases; Bousquet J, Addis A, Adcock I, et al. Integrated care pathways for airway diseases (AIRWAYS-ICPs). Eur Respir J. 2014;44(2):304-323.

53. Agarwal S, Perry HB, Long LA, Labrique AB. Evidence on feasibility and effective use of mHealth strategies by frontline health workers in developing countries: systematic review. Trop Med Int Health. 2015;20(8):1003-1014.

54. Agarwal S, LeFevre AE, Lee J, et al. Guidelines for reporting of health interventions using mobile phones: mobile health (mHealth) evidence reporting and assessment (mERA) checklist. BMJ. 2016;352:i1174.

55. Bhatt DL, Mehta C. Adaptive designs for clinical trials. N Engl J Med. 2016;375(1):65-74.

56. NHS_Choices. NHS Health Apps Library; 2016. Available from: http:// www.nhs.uk/tools/pages/toolslibrary.aspx. Accessed May 3, 2017.

57. Wu AC, Carpenter JF, Himes BE. Mobile health applications for asthma. $J$ Allergy Clin Immunol Pract. 2015;3(3):446-448. e441-e416.
Pragmatic and Observational Research

\section{Publish your work in this journal}

Pragmatic and Observational Research is an international, peer-reviewed, open access journal that publishes data from studies designed to reflect more closely medical interventions in real-world clinical practice compared with classical randomized controlled trials (RCTs). The manuscript management system is completely online and includes a very quick and fair peer-review

\section{Dovepress}

system. Visit http://www.dovepress.com/testimonials.php to read real quotes from published authors. 